\title{
FOREST PRACTICE IN CANADA, 1930
}

\author{
By B. F. Avery
}

$\mathrm{T}$

HE information contained in this report was obtained by means of a questionnaire. Data was furnished by Provincial Forest Services and by companies operating in forest products in Manitoba, Ontario, Quebec, New Brunswick and Nova Scotia.

Appreciative acknowledgment is herewith made of the prompt and complete replies received from those Companies and Government offices to whom the questionnaire was submitted.

This report is obviously incomplete. A complete survey of forest practice being followed in Canada would entail much time and effort and would require the appointment of several agents throughout the Dominion to collect the data.

It is considered that such a "running survey" of Forest practice is worth. while to the Canadian Society of Forest Engineers and it is respectfully recommended that the "machinery" to collect and to consolidate this data be established by the Society to the end that the membership may be kept informed, by means of an annual report not only of the extent of Forest practice but also of the details of method followed in handling definite forest problems in Canada.

Forest practice is a broad term. Assuming that it is the manifestation of an effort to apply the scientific basis of Silviculture to the establishment, development and protection of stands of timber, it must be concluded from the information submitted that there is a degree of Forest practice in Canada. The letters accompanying the questionnaire indicate more clearly than the resume statements the trend of effort. In some instances, attention is being given to establishment, protection and treatment of the forest because of the legislation compelling such a course. In other instances, attention has been turned toward certain aspects of Forest Practice because of an economic urge. In all instances there is indicated an appreciation of the fact of the relationship between the continuity of forest production and the development of Forest practice to meet the conditions encountered.

Further, it must be admitted that the number of cases in which forest conditions have been analyzed and a Forest practice undertaken to establish, develop and protect a forest for the production of the maximum in quality and in quantity of wood products are few and far between.

We have then, Forest practice in Canada or we have none, depending on the point of view of the individual making the statement. However, it is 
not the function of this report to prove or disprove either statement, but rather to state such facts as could be collected in the time given and by the means at hand.

It is interesting to note that in the case of each of sixteen agencies report. ing, an effort toward the practice of silviculture is being made over $100 \%$ of the area under its jurisdiction. The direction of this effort is along very much the same lines in the case of both Government and Industry. Five Government and three Industrial agencies are endeavoring to establish forests by artificial means while six Government and eight Industrial agencies are seeking the same end by natural means.

The answers with respect to treatment are inconsistent but the inconsistencies represent the spread between the effort of attention to the problem and the application of a method or of methods to effect the intent. Fifty. seven per cent in the case of "Government" and fifty-seven per cent in the case of "Industrial" are making an effort to treat the forest to improve quality. Approximately the same number are putting forth an effort to increase quantity production in each classification. However, under method of treatment we find that outside of experimental work, one "Government" and one "Industrial" have practised "cleaning," one Industrial "thinning," none "improvement" and two Government and three Industrial salvage cuttings. Salvage of fire killed and budworm killed timber in the highest degree possible appear to be the rule generally, but cleaning, thinning and improvement cuttings have not been undertaken to any extent. Pruning has been done experimentally and in one case by an industry in planted stands.

Under the heading "Protection" all agencies reporting are making an effort to protect against fire, five Government and eight Industrial against insects, two Government and five Industrial against fungi and three Industrial and three Government against other losses.

It is obvious that the pathological aspect of Forest practice has not been receiving a great amount of attention.

From the answers to the question, "Do you consider all or any portion of the area under your jurisdiction as being handled in such a way as to assure continuous production of wood equal to (or superior to) the quantity and quality production of the forest at the inception of management," there is evidently a great difference in the interpretation of the question. The Industrial answers convey generally that the areas being operated are being operated on a sustained yield basis. This means satisfactory regeneration on cut over land and growth equal to the annual cut. As there was no report of regeneration cutting very limited selection cutting and equally limited cutting with seed trees left as such, it is apparent that clear cutting with natural regeneration on the ground or coming in immediately after the cut, is the prevalent cutting practice followed. Areas under the jurisdiction of Govern- 
ment agencies are operated under clear cutting, selection cutting, and clear cutting with seed trees.

On the whole there has been a very small mileage of forests established by artificial means. Twenty-three and a half square miles of Government forest and eighteen square miles of Industrial forest have been so established.

It is of interest to note that one may find an example of nearly every aspect of Forest practice in Canada. It is of greater interest to realize the unanimity of effort to apply the scientific basis of silviculture in Forest Administration. The results of this effort will be interesting to the Society to watch and more interesting to the individual member to assist in effecting.

Editor's Note-Information of the nearest area furnishing a demonstration of any of the above listed aspects of Forest Practice is available at the office of the Secretary of the Society.

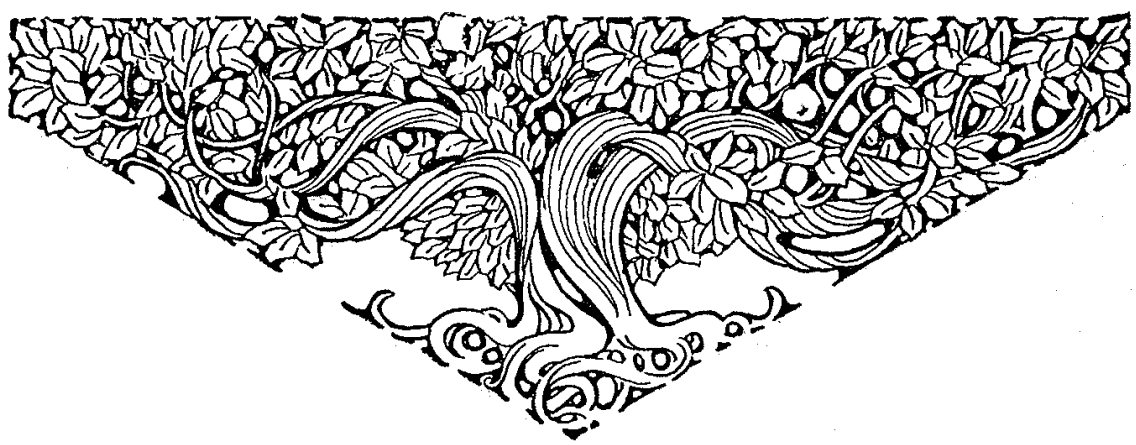

